\section{A Luz do Natal}

No Natal, as ruas das cidades e as nossas casas iluminam-se com uma luz especial. Hoje em dia, a maior parte da iluminação de Natal faz-se com LEDs, díodos emissores de luz (do inglês light emitting diode). A luz emitida por um LED, conhecida como luz fria, devido à ausência de irradiação na região do infravermelho, é praticamente monocromática. Os primeiros LEDs desenvolvidos emitiam luz vermelha e estiveram presentes nas nossas casas desde cedo, já que são maioritariamente utilizados em aparelhos eletrónicos para indicar que estão acesos. Se não fosse a crescente preocupação com os problemas ambientais e com a utilização racional dos recursos do Planeta, que promoveram uma intensa investigação em várias áreas da Química, o nosso Natal seria apenas um Natal de cor vermelha!

Os LEDs emitem luz por eletroluminescência, isto é, aplicada uma diferença de potencial, a emissão de luz

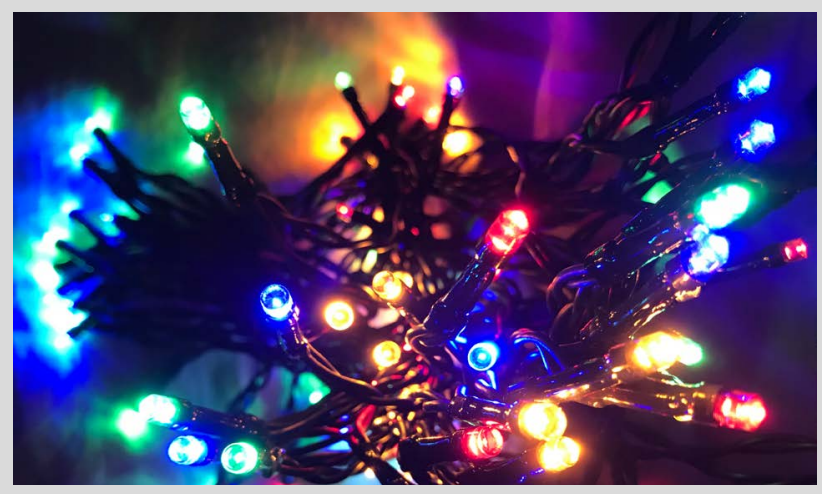

\author{
Marta Piñeiro \\ mpineiro@qui.uc.pt
}

ocorre quando os eletrões passam entre as camadas de material semicondutor de que é feito o díodo. Combinando vários semicondutores, nomeadamente, fosfeto de índio e gálio e alumínio (AIGalnP), nitreto de índio e gálio (InGaN), seleneto de zinco (ZnSe), fosfeto de gálio (GaP) ou nitreto de gálio (GaN) em diferentes proporções, são obtidas as cores que compõem o Natal!

Os LEDs mais difíceis de obter foram os de cor azul. Isamu Akasaki, Hiroshi Amano e Shuji Nakamura receberam, em 2014, o prémio Nobel de Física por desenvolverem o LED de cor azul, à base de nitreto de gálio. Os LEDs de luz branca, brilhantes e eficientes, podem ser LEDs emissores de cor azul (revestidos com uma camada de fósforo, que absorve a luz azul e emite a luz branca) ou os chamados RGB que são formados por três chips, um vermelho ( $\mathrm{R}$ de red), um verde ( $\mathrm{G}$ de green) e um azul (B de blue).

A iluminação com LEDs requer um consumo energético inferior ao das clássicas lâmpadas pelo que esta tecnologia promove a sustentabilidade através da diminuição do consumo energético. Um iluminado e sustentável Natal!

\section{Saiba mais em:}

Ci-Compound Interest, compoundchem.com/2016/12/14/leds (acedido em 09/11/2020).

Da Física à Química, mc2h2o.blogsspot.com/2011/12/o-brilho-do-natal.html (acedido em 09/11/2020).

InfoEscola, infoescola.com/eletronica/led-diodo-emissor-de-luz (acedido em 09/11/2020).

\section{Ouro, Incenso e Mirra}

No âmbito da quadra natalícia, a tradição diz que os três Reis Magos percorreram um longo caminho desde o Oriente para entregar três presentes ao Menino Jesus. Os três presentes eram ouro, incenso e mirra, claramente três presentes com muita Química.

0 ouro é um dos elementos da tabela periódica, com símbolo químico $\mathbf{A u}$, derivado do seu nome em latim aurum. 0 ouro é encontrado na natureza normalmente em estado puro, em forma de pepitas e depósitos aluviais. É um metal denso, amarelo,

\section{$>$}

\section{Marta Piñeiro}

mpineiro@qui.uc.pt

brilhante, maleável e dúctil. A sua durabilidade e o seu brilho metálico estão relacionados com o valor que lhe é atribuído desde tempos imemoriais.

0 incenso e a mirra têm uma química menos conhecida. 0 incenso, também conhecido como olíbano, é obtido de árvores do género Boswellia e desprende um odor característico quando é queimado. 0 aroma, muito intenso, é devido à presença de vários compostos denominados por terpenóides, tais como o ácido beta-boswélico e o incensol. Já a mirra é extraída 


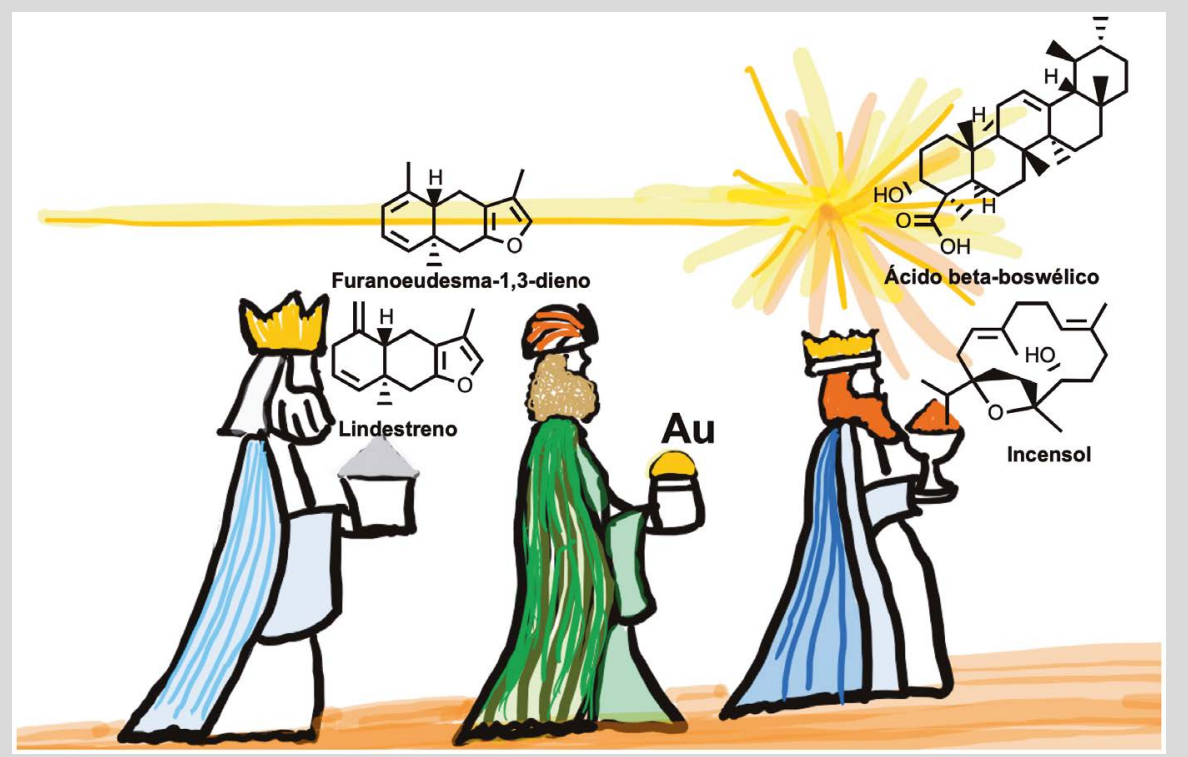

da Commiphora myrrha, da família das Burseraceae. A mirra é utilizada tradicionalmente na preparação de incensos e perfumes a que se atribuem diversas propriedades medicinais, nomeadamente anti-inflamatória, antimicrobiana e antioxidante. 0 seu aroma é proporcionado por furanosesquiterpenos, tais como o lindestreno e o furanoeudesma-1,3-dieno.

\section{Saiba mais em:}

B. Marongiu, A. Piras, S. Porcedda, A. Scorciapino, J. Agric. Food Chem. 2005, 53, 7939-7943. DOl:10.1021/jf051100x.

A. A. Mohamed, S. I. Ali, F. K. EL-Baz, A. K. Hegazy, M. A. Kord, Ind. Crops Prod. 2014, 57, 10-16. D0I: 10.1016/j.indcrop.2014.03.017.

Compound Interest, twitter.com/compoundchem/

status/547466843666272257/photo/1 (acedido em 09/11/2020).

School of Chemistry, University of Bristol, Incensole, chm.bris.ac.uk/motm/ incensole/incensoleh.htm (acedido em 09/11/2020).

\section{Cheira a Natal, Cheira a Canela!}

Marta Piñeiro

mpineiro@qui.uc.pt
Costumamos passar a época natalícia tão próximos quanto possível de familiares e amigos, e também rodeados de Química.

Com o Natal chegam as filhoses, os sonhos, o arroz doze, a aletria, as rabanadas,... e todas essas delícias que nos acompanham nesses dias em família. As nossas casas enchem-se de aromas que identificamos imediatamente e que nos despertam emoções e lembranças. Um desses aromas é o da canela.

A canela é uma especiaria obtida da casca de várias espécies de árvores do género Cinnamomum. A canela é, possivelmente, a especiaria mais conhecida desde a Antiguidade e também a mais popular nos nossos tempos. À canela são atribuídas diversas propriedades: estimulante, antisséptica, antimicrobiana ou anti-inflamatória, entre outras. Um estudo publicado em 2010 relaciona a ingestão de canela com a regulação do açúcar no sangue e da pressão arterial, o que é realmente conveniente após

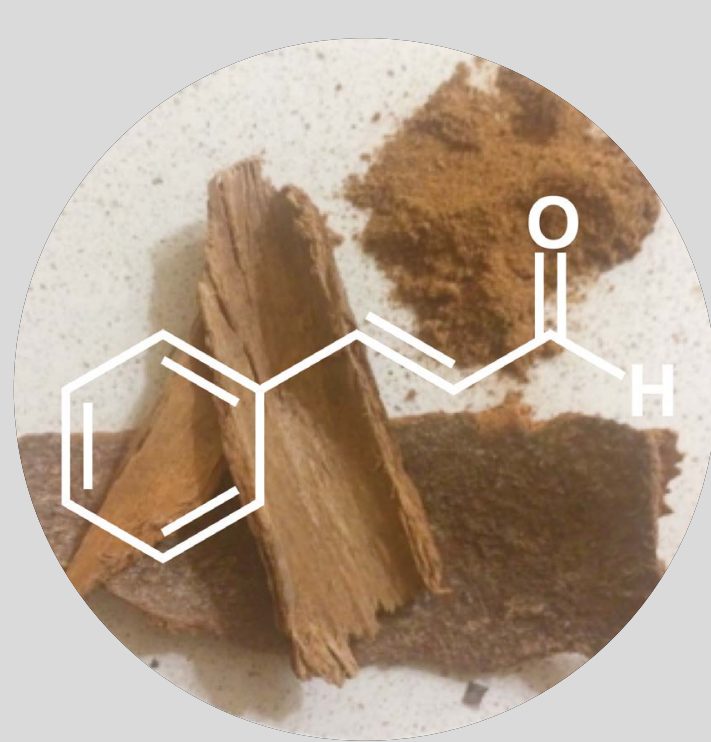

QUímicA | Vol. 44 | N. $0^{\circ} 157$ | 2020 | 149 
as, reconhecidamente excessivas, refeições natalícias!

O principal componente do óleo essencial da canela, responsável pelo seu odor e sabor, é o cinamaldeído, também denominado por aldeído cinâmico, trans-3-fenilpropenal ou (E)-3-fenilprop-2-enal. É um líquido viscoso e de cor amarelo pálido, parcialmente solúvel em água $\left(1,1 \mathrm{~g} / \mathrm{L}\right.$ a $\left.20^{\circ} \mathrm{C}\right)$, pouco mais denso que a água $\left(1,05 \mathrm{~g} / \mathrm{mL}\right.$ a $\left.25^{\circ} \mathrm{C}\right)$, funde a ca de $-7,5^{\circ} \mathrm{C}$ e tem um ponto de ebulição elevado $\left(248{ }^{\circ} \mathrm{C}\right)$. 0 cinamaldeído é muito volátil $\left(2 \mathrm{mmHg}\right.$ a $\left.25^{\circ} \mathrm{C}\right)$, pelo que esta pequena molécula se desprende facilmente do pau ou do pó de canela e viaja até os nossos recetores olfativos.
Reconhecemos imediatamente o aroma e ajuda-nos a viver a magia do Natal.

\section{Saiba mais em:}

C. S. S. S. Figueiredo, P. V. Oliveira, W. F. S. Saminez, R. M. Diniz, J. F. S. Rodrigues, M. S. M. Silva, L. C. N. Silva, M. A. G. Grisotto, Rev. Investig, Bioméd. São Luís 2017, 9, 192-197. DOI: 10.24863/ rib.v9i2.143.

R. Akilen, A. Tsiami, D. Devendra, N. Robinson, Diabet. Med. 2010, 27, 1159-1167. DOI: 10.1111/j.1464-5491.2010.03079.x.

Virgílio Nogueiro Gomes, Canela, virgiliogomes.com/index.php/cronicas/812-canela (acedido em 09/11/2020).

\section{Papel Térmico}

\section{Sérgio P. J. Rodrigues}

spjrodrigues@ci.uc.pt

Está em todo o lado. Nas contas de supermercado, nos pagamentos, nos restaurantes e multibancos. Imagino que muitos talões já tenham ficado manchados quando borrifados com álcool etílico (agora ainda mais nestes tempos de pandemia em que constantemente estamos a desinfetar as mãos com soluções à base daquele álcool...). Porque será? Já se perguntaram? 0 álcool etílico (atualmente ubíquo) não atua como um reagente, mas como um solvente, permitindo que os reagentes reajam (se combinem entre si) na presença deste solvente. Obviamente, a água, como solvente, não deverá ser eficaz na promoção desta reação pois, nesse caso, qualquer humidade e suor marcaria o papel. A ideia do papel térmico surgiu nos anos sessenta do século passado e agora quase todos o utilizam. Contando com centenas de patentes, artigos e relatórios, o processo foi-se aprimorando. Basicamente temos matrizes sólidas de corante incolor e do respetivo revelador que se juntam quando o papel é aquecido, por exemplo, um corante e o bisfenol A (BPA), tal como mostrado no esquema.

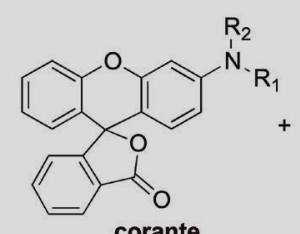<smiles>CC(C)(c1ccc(O)cc1)c1ccc(O)cc1</smiles>

BPA

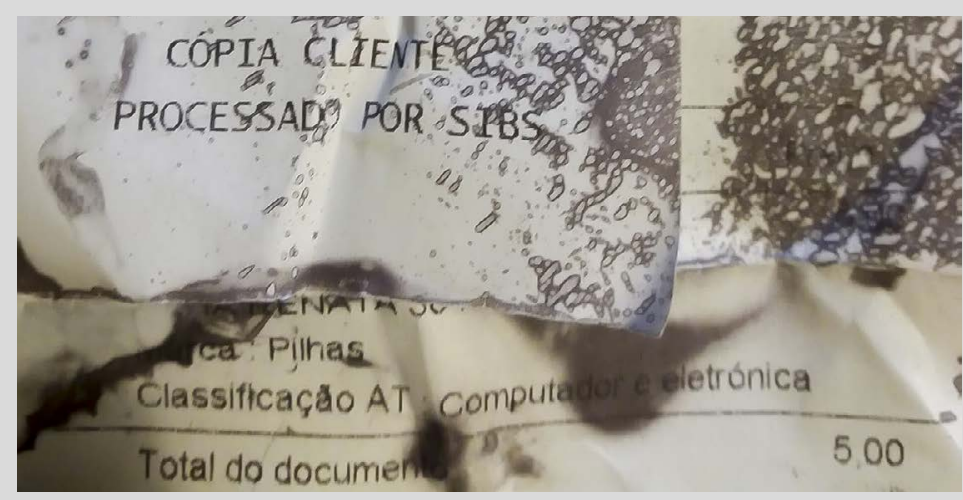

Talões em papel térmico

Mas claro, a investigação e o desenvolvimento não ficarão por aqui. A restrição à utilização de BPA na União Europeia (UE) impulsionou centenas de cientistas em instituições e indústrias a procurar alternativas e melhorias. Querem que o papel seja mais resistente à luz solar ao longo do tempo. Querem que o processo e os materiais sejam ainda mais seguros e sustentáveis. Tudo isto são oportunidades. No papel, nos corantes, nos reagentes, nos protetores solares. A próxima vez que pedir o número de contribuinte ou o talão pense nisso.

\section{Saiba mais em:}

M. K. Börnsdotter, J. de Boer, A. Ballesteros-Gomez, Chemosphere 2017, 182 , 691-706. DOI: 10.1016/j.chemosphere.2017.05.070.

"Passeio à procura do papel térmico", percursosquimicos.blogspot. com/2020/06/passeio-procura-do-papel-termico (acedido a 28/07/2020). 